\title{
2nd Special Issue dedicated to the Best Oral Presentations given during the XVIII International Conference Sol-Gel 2015 held in Kyoto, Japan, September 6-11, 2015
}

\author{
Hiromitsu Kozuka ${ }^{1}$
}

Published online: 30 December 2016

(C) Springer Science+Business Media New York 2016

This January issue of the Journal of Sol-Gel Science and Technology is the 2nd Special Issue dedicated to Sol-Gel 2015, the XVIII International Sol-Gel Conference held in Kyoto, September 6-11, 2015. The first one was published in the Journal of Sol-Gel Science and Technology as Volume 79, Issue 2, and contained the contributions of the Keynote, Invited and Award winning (Ulrich and best posters) presentations.

The organization of this second issue was suggested during the meeting that the JSST Editors and members of the International Advisory Board (IAB) had during the Sol-Gel 2015 conference. It contains for the first time sixteen contributions submitted by those who made the most interesting oral presentations according to the chairs of each session. I would like to add the following comments about the procedure for building up the scientific program of the conference. First the Local Organizing Committee (LOC) asked the International Advisory Board members to nominate invited speakers. Thanks to the great cooperation with the IAB members, the LOC could have excellent plenary and invited speakers. As for the contributed papers, we were very happy to have the abstracts submitted for oral presentations, which were much larger in number than the slots we prepared for oral presentations. The Scientific Committee (SC) members made great efforts to select oral presentations, reading the submitted abstracts very carefully in order to make the final version of the scientific program.

Hiromitsu Kozuka

kozuka@kansai-u.ac.jp

Kansai University, 3-3-35 Yamate-cho, Suita 564-8680, Japan
I would like to thank all IAB and SC members for their great contribution on realizing such an excellent scientific program of Sol-Gel 2015. I also would like to thank the session chairs for their efforts in selecting the best oral presentations for this Special Issue. I appreciate their efforts and express my thanks by listing their names

International Advisory Board

M. Aegerter, R. M. Almeida, D. Avnir, B.-S. Bae, J. Bartlett, J. C. Brinker, B. Dunn, M. Guglielmi, N. Hüsing, Q. X. Jia, D.-P. Kim, K. Kuroda, D. Levy, J. J. E. Moreau, S. J. L. Ribeiro, C. Sanchez, and H. Yang

Scientific Committee

H. Imai, M. Kakihana, K. Kato, H. Kozuka, A. Matsuda, Y. Sugahara, K. Tadanaga, M. Takahashi, and T. Tsuru

Session Chairs

R. M. Almeida, F. Babonneau, S. A. Bilmes, R. Caruso, Y. Daiko, M. Guglielmi, X.-Z. Guo, P. Innocenzi, A. Jitianu, K. Kanamori, K. Katagiri, K. Kato, V. Kessler, D.-P. Kim, M. Lindén, L. Malfatti, A. Matsuda, J.-M. Nedelec, S.-K. Park, A. Shimojima, Y. Sugahara, K. Tadanaga, M. Takahashi, A. ten Elshof, T. Tsuru, M. Wong Chi Man, and K. Yao

Hiromitsu Kozuka

Co-Chair and Head of Scientific Committee of Sol-Gel 2015 